severe and intubation was performed with immediate relief. One thousands units of antitoxin were administered. The tube was removed on the fourth day, dyspnea returning in a few hours, and reinserted six hours after extraction. It was again removed two days later and dyspnea did not return until four days after the second extraction, when intubation was again urgent, a piece of membrane being loosened as the tube was inserted. One thousand five hundred units of antitoxin were given and, although the tube was coughed out twice during the next four days, on extraction the breathing was good and the patient recovered. The conclusions from this case, contirmed by later experience, show that if the tube can not be removed at the end of four days an additional 1500 units of antitoxin should be given. The retained tube was evidently necessary on account of persisting membrane, showing the original dose of 1000 units insufficient for this case. The tube was worn ten days.

CASE 2.-A girl, aged 2 years and 9 months, was seen with Dr. Rodd, Feb. 2, 189\%. A glance at the child was sufficient to show that the marked cyanosis and comatose condition promised a speedily fatal termination. A three-year tube was quickly prepared and, with only a nervous woman as assistant, and no one to hold the head, an attempt was made to pass the tube, but the faulty position and large size of the tube made two efforts unsuccessful, and it was at once apparent that one more failure was certain to prove fatal. I exchanged the three-year tube for the one-year size, and at this juncture Dr. Rodd arrived. Our next effort was successful and no more inspiring or delightful sight can greet the eyes of the surgeon than this picture of returning life to the asphyxiated child. An hour later the one-year tube was coughed out, and a two-year replaced it. The case progressed favorably but reiutubation was necessary on the fourth, sixth, eighth and tenth days. A loose piece of membrane was removed at one of these operations and 1000 units more given. The tube was finally removed on the seventeenth day, twelve intubations having been performed.

A case which illustrates the possibility of saving life when the patients are moribund was seen with Dr. Geo. Bassett, May 25, 1897. A boy, aged 3 years and 5 months, had been ill with diphtheria involving the tonsils, pillars and larynx for some days and no physician in attendance. On entering the room it seemed that death was a question of only a few minutes. There was no radial pulse and the child was completely comatose. It luckily happened that a three-year tube prepared for another patient was ready for use, and as the tissues were completely relaxed it was quickly passed without disturbing the position of the child on the bed, and artificial respiration resorted to. The tube gave perfect relief and the patient was sent to the hospital for treatment, 1500 units of antitoxin having been given. On the fourth day the tube was extracted, but dyspnea returning next day a second operation was performed and 1000 units administered. He coughed out the tube 21/2 days later, and was discharged from the hospital fully recovered fifteen days after admission.

From a study of these cases and general observations in the treatment of diphtheria, we can formulate a series of definite conclusions and rules of procedure which apply to all cases of laryngeal diphtheria.

1. Administer antitoxin early without waiting for a bacteriologic diagnosis.

2. Tonsillar exudate attended by a croupy cough or partial aphonia is an indication for a full dose of 1500 2000 units of antitoxin.

3. Antitoxin administered twelve hours or more prior to operative interference will reduce the mortality of intubated cases at least 50 per cent.

4. Immunize all exposed children of croup age.

5. Continuous steam inhalations are of great value in all cases.

6. Early operation is most strongly advocated. SUMMARY OF ONE IIUNDRED CASES.

Number of operations, 100 ; recoveries, 69 ; deaths, 31 ; mortality under 3 years, 49 per cent.; mortality over 3 years, 19 per cent.; complicating measles, 8 cases, 5 deaths.

Age of patients operated on: 1 to 2 years, 16, of whom 9 recovered, 56.25 per cent.; 2 to 3 years, 23 , with 11 recoveries, 47 per cent.; 3 to 4 years, 20 , of whom 16 recovered, 80 per cent. ; 4 to 5 years, 15 , of whom 12 recovered, 80 per cent.; 5 to 6 years, 11 cases, with 10 recoveries, 90.9 per cent.; 6 to 8 years, 10 , of whom 7 recovered, 70 per cent.; 8 to 12 years, 5 , of whom 4 recovered, 80 per cent.; number of doses of antitoxin, 160.

Eighty-five per cent. of the cases occurred on streets that were not paved.

\section{USE OF OPIUM IN INFANCY, SEEN IN ADULT LIFE.*}

BY T. D. CROTHERS, M.D. SUPERINTENDENT WALNUT LODGE HOSPITAL. HARTFORD, CONN.

The danger of opium as a remedy in infancy has only recently been recognized. Many physicians give the drug or its alkaloids without the slightest recognition of its possible injurious effects on the organism in the future. In a recent text-book, a statement is made that the action of opium is transient in infancy, and without danger except in large doses. The prominence of certain proprietary drugs, as soothing syrups for children, and the characteristic effects of opium, with the great injuries noted later, have brought out facts of the damage from these sources.

In current literature little notice is taken of this danger, and yet a great variety of facts are constantly appearing, pointing out the disease and degeneration clearly traceable to this cause. In all probability the largest use of opium in infancy comes from its domestic application. The various tinctures and infusions are household remedies and, in many sections, the gum from the poppy is gathered and put away regularly as a household necessity. It is the most convenient and practical of all remedies in the obscure disturbances of childhood. No doubt, some physicians find it very useful and often give it thoughtlessly. The drug store files show how commonly it is used in infantile therapeutics, and often it is given in a routine way for a long time, particularly for neurotic and intestinal disorders.

My purpose is to call renewed attention to this danger, and show some new facts from the clinical side, that are not uncommion and, no doubt, can be confirmed in the practice of many physicians.

In adult life, opium and its alkaloids, in a general way, are marked excitants or depressants. Either one or the other is most prominent, and both always are in the same person. This is not dependent on the doses, although that is marked in many cases. One will have a long, early stage of stimulation and wakefulness, and

- Presented to the Section on Physlology and Dietetics, at the Fiftieth Annual Meeting of the American Medical Association, held at Columbus, Ohio, June 6-9, 1899. 
then depression and sleep. The other will have only slight exhilaration, and rapid marked sedation. In one case recovery from its narcotic action is followed by malaise and much physical discomfort; in the other, rest and a degree of satisfaction resembling that which follows natural sleep. The psychic effects vary: In one, most pleasing mental quietness and satisfaction follow; in the other, unusual buoyancy followed by total oblivion and discomfort and recovery. In the former, the mind falsely reasons that some new, exalted mental condition has been attained, most desirable for the future. In the latter, the discomfort from reaction calls for relief in the removal of the drug. Both classes soon have a reactionary period of discomfort and nerve disturbance. These are general states to which there are almost infinite exceptions and variations. While the sedation from opium falls most markedly on the sensory centers, and nerves of sensation, its localized action on the psychic and organic functions varies widely. In one case profound alterations of the functions appear, and rapidly extend to the mental operations. The organism, after a period of sharp irritation, apparent in nausea and deranged digestion, seems to take on a certain inmunity and toleration, or the organism appropriates opium as it does food, and a demand for its continuous use becomes more and more imperative. This is the state of the habitués, and is the result of a long use of it, or appears in some cases at the beginning of its use. It is evident that some unknown states of the organism are more susceptible to its physiologic action than others. It is a common observation that coarse, low organic natures, or imperfectly developed minds and bodies are less susceptible to the sedative effects of opium than high-grade, finely developed, nervous persons. In practice, opium as a medicine varies in its effects very largely from these conditions-the finer the organism, the more pronounced the effects and the smaller the dose required; the coarser the organism, other things being equal, the larger the dose to get its physiologic action. These general facts, with others, are the same in infancy as in adults, only less observed. The child who is given laudanum for some condition, and appears better, has had the pain distress-signals covered up, and at what sacrifice, or organic changes which follow, no one can tell. At all events, the same exhilaration and depression occur as seen in the adult. The former may not be noticed and the latter only seen, but the same conditions follow. In the infant the small power of resistance and the extreme susceptibility to physiologic influence from narcotics is not overcome by dosage. The physiologic action of $1 / 2$ gr. of opium on an adult, and in $1 / 40$ gr. on an infant is the same in degree, only in one case there is little or no resisting power. The infant has an unknown and undeveloped organism. The adult is, in some degree, known, and certain physiologic effects may be confidently expected. It is not a single dose or several doses given for certain disorders, although this is often marked in many ways, but it is the long-continued use that is followed by certain degenerations.

Opium given in convulsions, with other drugs, and in intestinal troubles, and for insomnia, nervous irritation and unknown conditions, with apparent good results in temporary relief, is dangerous if continued any length of time.

Opium and its alkaloids seem to have two distinct effects on the nerve-centers and organism of infancy. Its sedative action is of the nature of palsy. Cell functions and growths are slowed up, retarded and finally changed. The changes following long-continued doses become permanent. The symptoms of dulness and stupor continue in lessened vigor and degrees of imbecility and mental perversion in later life. The freedom from pain and forced sleep with apparent steadiness of nerve force react in increased irritation and instability, with greater sensitiveness to all surroundings.

Nearly all persons who have been injured in infancy and early childhood from these drugs manifest these two characteristics. Increased dulness and stupor, or nerrous irritation and instability, often both, may be combined in one. Beyond these are disorders of the nervous system and digestion, with low power of control and subject to morbid impulses that are largely uncontrollable. These various manifestations are better studied in the history of cases, the following of which are illustrations.

In a family of four children, whose parents were strong, healthy persons, living on a farm, one, a boy, was dull, passionate and of a low grade of intellect. He would overeat and drink to excess, water, tea, coffee, or anything he fancied. He was stupid and obstinate, and at times, excessively sensitive and irritable. No one in the family resembled him in any way, but all were healthy and vigorous in mind and body. When 1 year old he had a convulsion and was given opium daily for over a year. Then at long intervals, finally, it was abandoned, and it has not been used since. The parents noticed it was affecting him at the time, changing his mind and habits, and would not permit its use again. This was clearly an example of retarded brain growth with perversion of the functions, and later it will, no doubt, develop into some drug addiction or low form of dementia, disease and death. The history pointed to its use as the most prominent cause of this condition.

In a similarly healthy family, one son became an im. pulsive inebriate at 18 years of age. The others in the same surroundings and conditions of living are very temperate and well. During the infancy of this boy he was given morphia for intestinal disturbances. At one time it was taken for nearly a year, by advice of the physician. He was stupid and dull much of the time this was taken, and its use was continued as a medicine for years, at long intervals, and in one or two doses a day. He began to use spirits to excess soon after puberty, and is now a periodic inebriate. The clinical study indicated a degree of mental and physical perversion and degeneration, dating from the use of morphia in infancy. A case which came under my observation was that of two children of a distinguished missionary, one, a young woman, who at 24 years of age suddenly began to use opium and spirits to excess and showed much mental disturbance. During infancy she was nursed by a Hindoo woman, and was noted for her stupor and tendency to sleep: In early and later childhood she was extremely nervous and suffered from many hysterical affections. She was an accomplished teacher and a woman of great pride of character and ambition. Her brother, born two years later, was nursed by the same woman, and was noted for his somnolence and general stupor during this time. Iater it was found that the nurse was an opium-taker, and that both children had been under the influence of opium from nursing. The boy grew up extremely nervous and irritable. At one time he drank beer to excess, then was a gambler. He was changeable and notional, became a clergyman; then a physician, and finally a speculator. $\mathrm{He}$ is now an opium-taker and neurasthenic, and invalid, although not 30 years of age. Two other children of this family, one born before this Hindoo wornan became a nurse, and the other after she was discharged, are strong and healthy 
and free from any peculiarities of mind or body. The elimination of all other cases leaves the poison of opium the specific central factor in these cases. In my studies of the heredity of all alcoholic and opium inebriety, about 10 per cent. give some history of drugging in infancy. Paregoric and laudanum are the most common. Narcotism from opium by accident has been followed by defects which finally culminated in drug or spirit-taking. A boy, 2 years old, ate a large number of opium and candy lozenges and was narcotized for two days, and with difficulty prevented from dying. He grew up an erratic, unstable, and feeble child. Digestion was impaired and sleep broken, and finally, at 21 , he became a spirit-taker and inebriate. Two brothers were healthy and strong. This was probably the result of narcotism. In cases of defective parentage, where nervous degeneration and unsoundness exist, the use of opium in infancy will intensify these states, and make them more pronounced. In children from drug-poisoned families, such as inebriates or those who, from nutritional disorders are suffering from autointoxication, opium may prove a most seductive drug for a time, but in the end be followed by more serious evils. Children of brain-exhausted, worn-out parents are often found to enjoy the effects of opium, and receive great apparent benefits from its use. Later they easily become drug-takers, and are the most incurable. Neurotic infants and children are, no doubt, very susceptible to these drugs, and the physiologic impression is so pronounced as to suggest organic changes.

A few instances are on record of hydrocephalus following the use of opium in children, suggesting serum in the ventricles, ending usually in exhaustion, coma and death. Many parents manifest an unreasoning therapeutic credulity in drugs in infancy, which pinysicians cultivate and sometimes heartily believe in. In such a case a very strong medical man continued an opium prescription for over a year, and the child grew up feebleminded and is now an invalid. The next child in the same family is a hearty, vigorous man. $\mathrm{He}$ was not treated for any length of time during childhood by drugs. The use of laudanum in infancy was traceable in ten cases of epilepsy associated with spirit drinking and petty criminality. As these patients came from the lower classes and had a defective heredity, the influence of opium could not be separated as a specific cause. Undoubtedly, it was a large contributing one. I have gathered many histories which seem to confirm the impression that opium-taking in infancy and childhood is often an exciting cause of a latent hereditary predisposition to the drink mania. At all events, a large proportion of such persons seek relief from alcohol in the physical strain and stress of life, then take opium when the effects of alcohol become prominent.

Opium and its alkaloids, given to healthy children occasionally for some special purpose, are in all probability without injurious effects. In unhealthy, neurotic children, with defective ancestors, and evident imperfect development, the increased degeneration which follows the use of opium is clearly from this source. Where this drug is combined with other remedies, and given a long time, the effects are the same. They can not be lessened by the action of other drugs. No form of opium should be given to infants or children for more than a day at a time. While the effects of continuous sedation may be overcome by correct living, the cell injury and perversion of function is never repaired. The growth and development of other organs may do much to overcome in part, and cover up the injury, but the defects will appear from the presence of the slightest exciting cause. The following case has recently come to my notice.

Five children of healthy parents became inebriates, both alcoholic and opium, when about 20 years of age. There was no heredity nor any special exciting causes. The home life and example were good, and both parents were total abstainers. Fach one seemed to be nervous and feeble, and lacking in vigor, then without any reason began to use alcohol and opium freely, and finally were addicted to its constant use. It was found that from early infancy and through childhood they had been given laudanum and other forms of opium, for all sorts of ills. The mother had treated them without the aid of a doctor, and opium was used continuously for several months at a time. They all suffered from nutritional and digestive disorders, and were all nervous insomniacs and irritable and dull at times. This domestic treatment was, no doubt, the cause of the degeneration and neurosis in manhood. Three of these persons are decidedly feebleminded. One is a talented musician, the other an actor of some ability. Two use spirits alone; two use alcohol and opium; one uses opium alone. They are of the imbecile grade of inebriates.

Another case reported to me was that of a very highly cultivated woman who, at 34 , began to use morphia without any apparent cause in pain or sickness. She was a philanthropist and on the visiting board of a hospital where such cases were treated, and was acquainted with the dangers of the use of the drug. All the possible causes were eliminated in the study and the remarkable fact appeared that opium was used very freely in the tirst two years of her life. It was with difficulty removed and she was feeble and very nervous until after puberty, when she became strong. Her own statement was that she found such peace and comfort from its effects that she could not abstain from it.

Several persons using alcohol have given, as a reason for this addiction, the fear of becoming opium-inebriates, They have found opium so seductive and pleasing as to be irresistible; with alcohol they felt safe. Opium-taking in infancy is the common history of many cases, and is generally the domestic use of laudanum at first, for disorders of mind and body.

The presence of nervous dyspepsia, which begins soon after puberty and by early or middle manhood becomes a most distressing disease, is often traceable to the free use of opium in infancy and early life. Early and profound exhaustion from slight overwork or excitement, seen in young persons, indicating low vitality and feeble nervous organism, is the result of opium-taking early in life. Early precocity or failure to sustain the expectations created have been noted in the cases of early addiction. The many constitutional defects and degeneracies which appear after puberty and in early manhood should always create an inquiry concerning the early therapeutics and drugs given in childhood. Where soothing syrups and prescriptions for seductive effects have been used a long time, the suspicion is strong that an opium diathesis has been created. I wish to emphasize that the use of opium and its alkaloids in infancy will, in a large proportion of cases, create a diathesis or predisposition to its use in later life. This predisposition is manifest in irritation and exhaustion, wth intense, uncontrollable impulses for relief.

Alcohol, chloroform, chloral and many of the most common narcotics are welcomed and largely used to supply this demand. This opium degeneration may take on sexual and nutrient manias and leave the brain in an infantile condition of vigor and stability. A "Christian 
Scientist" who has made some reputation by his delirious theories, was, according to a Boston physician, brought up on opium. His mother was a narcotic, and to protect herself, gave her son opium freely in early life. $\mathrm{He}$ grew up undersized, and with a highly sensitive brain, full of delusive dreams and fantasies. This was another form of opium diathesis.

The second fact that I would note is that opium in infancy acting on the most unstable organism, the brain cells and centers, not only retards but prevents healthy physiologic growth. In defective heredity this is permanent, although it may be concealed until later in life. This physiologic action of exaltation and depression, the latter being the princinal stage, is manifestly toxic and injurious from the functional derangement which follows. Where no disturbance is recognized, the real danger is concealed. The cell growth and functions suffer, mechanically, nutritionally and psychically, by checking activity, diminishing nutrition and changing direction and purpose of action. This is true of opium in all cases. Sometimes one effect is more prominent than others. In DeQuincy the psychic action was prominent. In some cases the anemia shows in the disturbance of nutrition, and in others the depression and suppression of organic activity is apparent.

The third fact to be remembered is the concealed danger from opium-drugging in infancy. If only neurosis is present, if defects of growth and function exist, opium will of necessity increase this condition. Anemia, exhaustion and perversion of organic activity follow. If some temporary state is present, opium, by covering up the pain-signal is not curative, but may be destructive in many ways not easily recognized until later in life. No one can tell whether this danger begins with the first dose or only after a succession of doses.

Lastly, the magnitude of this danger is not recognized as it will be in the future. Neurotic disturbances, obscure and open, and toxic diseases of many forms, have an early history of opium drugging. The ignorant mother who uses soothing syrups freely, to suppress the irritation of the infant, is not the only offender. The routine, and often thoughtless, physician who uses opium freely in infantile prescriptions is responsible in many ways for the wrecks of later life. The toxic cases under my care are striking illustrations of this evil. Inquiry in others brings out this cause with great frequency. While it is difficult to narrow down the etiology to this one factor, it is clear that the danger from this source has been and is a potent and wide-spread cause. We need more clinical researches and clinical studies in this direction.

\section{THE BUBONIC PIAAGLE IN SAN FRANCISCO.* BY W. H. KELLOGG, M.D. CITY BACTERIOLOGIST. SAN FRANCISCO, CAL.}

We have always regarded the plague as something very distant and impossible, and have read of its ravages in India and China with much the same feeling of composure and security that we read about an uprising of the natives in Madagascar. Or perhaps we have considered it as a matter of historic interest on account of the fearful epidemics which in pre-sanitary days used to sweep over Europe, devastating countries and hardly leaving enough people behind to keep up the archives and records of the state. Even now that it is among us, and in America for the first time, there seems to be a

* Read before the San Francisco County Medical Soclety. tendency to underrate its importance and dismiss it without a thought, as a scare designed for base political motives.

While I do not believe in becoming unduly excited about it, or in publishing far and wide that there is plague in San Francisco, I do not think that we should try to deny among ourselves the very existence of it, but should accept the situation as it is and do our best to stamp it out while it is still within our power. It would be folly to ignore its presence and allow it to increase to such an extent that the national government would be compelled to step in and take from our hands the work of fighting it and perhaps quarantine the whole city with U. S. troops, thus advertising to the world that San Francisco was not only financially negligent in the face of an epidemic of a disease which is guarded against by the U. S. Marine-Hospital Service with more watchfulness and dread than any other.

San Francisco should look at the history of Oporto, and profit by her experience. The bacteriologist who announced the first case, in January, 1899, narrowly escaped being mobbed. The health authorities were hampered by the merchants and the press, who harped on the injury to trade caused by the announcement of the existence of plague which the laymen, in their infinite wisdom, declared did not exist. The health authorities were refused assistance until finally so many cases appeared that the government stepped in, surrounded the city with a cordon of soldiers, absolutely stopping all travel and business, and it was only after the lapse of one year, and after the experience of a partial famine, that the city was released and declared no longer infected. In the meantime its citizens had parted with the small sum of $\$ \%, 000,000$, a good deal of money, but the probability is that by that time, even the omnipotent and scientifically wise press had arrived at the conclusion that their lives were more valuable than their business.

Just how the disease was introduced into this country is a mystery, as the first case discovered was in a Chinaman who had been in Chinatown sixteen years. The probability is that he was not the first, and this theory is strengthened by the fact that there had been an increased mortality in that district during the months of January and February. During those months there were 97 deaths reported from the Mongolian quarter, and of these 20 were ascribed to lobar pneumonia, 5 to bronchopneumonia, 4 to typhoid fever, and 7 to acute miliary tuberculosis. Now all of these diseases, in the beginning of an epidemic of plague, should be regarded with suspicion, and examined bacteriologically, for they are simulated very closely by the pest.

The assistantcity physician, whose duty it is to inspect all dead Chinese who have died without attendance by $\mathbf{a}$ regular physician, is at a great disadvantage in arriving at the cause of death. He simply sees the body after death, and by questioning the relatives or undertaker, who are ignorant and use very broken English, he makes a guess at the cause of death, taking into account the appearance of the body. According to the Caucasian statistics of San Francisco, the number of deaths from pneumonia, typhoid, and miliary tuberculosis, to every 97 deaths, would be 12.3 , whereas the assistant city physician, with the means at his conmand, has been forced to consider that there were 36 of these cases out of a total of 97 deaths for the two months. Since the plague can readily be mistaken for these diseases, we are justified in the suspicion that some of these cases were plague. Nor is the fact that we have not now a wide- 